\title{
NEONATAL CHOLESTASIS AND BILIARY ATRESIA: PERSPECTIVE FROM MALAYSIA
}

\section{Lee WS}

Department of Paediatrics, Faculty of Medicine, University of Malaya, Kuala Lumpur, Malaysia.

\begin{abstract}
:
The liver is an important organ of the human body, playing a major role in the metabolism and storage of nutrients, synthesis of protein and other nutrients, as well as detoxifying many metabolic by-products. The response of the foetal and newborn liver to external insult and injury is limited. This is because the ability of the closely interdependent structures of a developing liver of expressing in the face of a variety of insults is limited as well. Thus most infants with insults to the liver present as cholestatic jaundice with variable degree of pale stools, enlarged liver and conjugated hyperbilirubinaemia. Biliary atresia, an idiopathic condition characterized by progressive fibrosing obliteration of both intra- and extrahepatic bile ducts, is the most important cause of neonatal cholestasis worldwide, including Malaysia. It is also the most important indication for childhood liver transplantation the world over. Challenges facing infants with biliary atresia include a delay in the diagnosis and late surgery, leading to a poor outcome. This often results from a failure to recognise the potential serious nature of an infant with prolonged cholestatic jaundice and pale stools among health care professionals. (JUMMEC 2010; 13(2): 72-79)
\end{abstract}

KEYWORDS: neonatal cholestasis, biliary atresia

\section{Introduction}

The liver is the largest organ of the human body. It weighs approximately 2 to $2.5 \%$ of the total body weight of a healthy adult. The liver plays a major role in the metabolism and storage of nutrients, synthesis of various proteins and coagulation factors, as well as detoxifying many metabolic by-products (1).

\section{Embryology of the liver}

In the human embryo, the liver is derived from the endoderm, one of the three germ layers formed from gastrulation (2). It first appears as a hollow endodermal bud derived from the foregut. Hepatoblasts, the progenitor of liver cells, derived entirely from this budding endoderm, are identifiable from about 28 days (2). The vascular sinusoidal network of the embryonic liver is derived from the mesodermal layer. Bile ducts are derived from two distinct elements. Intrahepatic bile ducts appear from about seven weeks while the extrahepatic bile ducts are derived from the budding foregut endoderm (2). The weight of the liver of a newborn is approximately $200 \mathrm{~g}, \sim 5 \%$ of the body mass. This is very small compared to the liver of a full grown adult which weighs approximately $1.2-1.8 \mathrm{~kg}$ (2).

The main driving force in the generation of bile flow in early life is the hepatocyte secretion of bile acids. There are evidences to suggest that there is a period of 'physiological cholestasis' associated with immature or altered metabolism and transport of bile acids at birth (3). This may be due to a combination of structural and functional immaturity of the hepatic excretory functions in the newborns (4).

\footnotetext{
Correspondence:

Lee Way Seah

Department of Paediatrics,

Faculty of Medicine

University of Malaya

59100 Kuala Lumpur, Malaysia

Email: leews@um.edu.my
} 


\section{Neonatal cholestasis}

The response of the foetal and newborn liver to insult and injury is limited. This is because the ability of the closely interdependent structures of a developing liver, i.e. hepatocytes, small intrahepatic bile ductules, large extrahepatic bile ducts, of expressing in the face of a variety of insults is limited as well (5). Injury to the newborn liver usually manifests as neonatal cholestasis. Clinically, this manifests as variable degree of pale stools and enlarged liver, and biochemically as prolonged conjugated hyperbilirubinaemia $(6,7)$.

\section{Causes and clinical features of neonatal cholestasis}

Many causes have been identified to cause injury to the newborn liver $(8,9)$. These may include intrahepatic causes, which may be either sporadic or familial, and extrahepatic causes (8). In the 146 cases of neonatal cholestasis referred to the Paediatric Unit of University of Malaya Medical Centre (UMMC), Kuala Lumpur, approximately $30 \%$ of cases were eventually found to have biliary atresia (BA, Table 1) (8-10).

Most of the infants with liver injury present ascholestatic jaundice with variable degree of pale stools and enlarged liver (7). There are considerable overlap in the clinical features of various cause of neonatal cholestasis (Table 2) $(7,11)$. Jaundice is a universal clinical features of neonatal cholestasis (7). However, there is no evidence to suggest that infants with BA have an earlier onset or more severe degree of jaundice than those with other causes of neonatal cholestasis (11). In addition, it is also impossible to differentiate the underlying cause of neonatal cholestasis based on the size of hepatomegaly (11). Hence, it is important to realise that each of the presenting features of neonatal liver disease is an imperfect way of discerning the underlying cause of the cholestasis. It is always a challenge for paediatricians to identify the underlying cause of the insult to liver even though their clinical manifestations may be very similar $(7,12)$.

\section{Importance of early diagnosis}

The majority of infants with cholestatic liver disease present during the first month of life (13). Thus, prompt and efficient differentiation of cholestatic jaundice from common physiological hyperbilirubinaemia of the neonate or the prolonged jaundice occasionally associated with breast feeding is essential (14). This is because in BA, when hepatoportoenterostomy is

Table 1: Major causes of neonatal cholestasis seen at the University of Malaya Medical Centre, Kuala Lumpur; 1996 - 2004

\begin{tabular}{|c|c|c|}
\hline Underlying causes & $\mathbf{N}$ & $\%$ \\
\hline \multicolumn{3}{|l|}{ Bile duct obstruction } \\
\hline Biliary atresia & 42 & 29 \\
\hline Other causes & 4 & 3 \\
\hline \multicolumn{3}{|l|}{ Infections } \\
\hline Idiopathic & 56 & 38 \\
\hline Cytomegalovirus & 13 & 9 \\
\hline Other infections & 5 & 3 \\
\hline Progressive familial intrahepatic cholestasis & 5 & 3 \\
\hline Endocrine causes & 5 & 3 \\
\hline Metabolic causes & 3 & 2 \\
\hline Acute liver failure & 4 & 3 \\
\hline Parenteral nutrition-related cholestasis & 7 & 5 \\
\hline Perinatal asphyxia & 2 & 1 \\
\hline Total (\%) & 146 & 100 \\
\hline
\end{tabular}

Adapted from: Lee WS, et al. Aetiology and outcome of neonatal cholestasis in Malaysia. Singapore Med J 2010; 51: $434-439$. 
Table 2: Clinical features of neonatal cholestasis seen at the University of Malaya Medical Centre, Kuala Lumpur; 1996 - 2004

\begin{tabular}{|c|c|c|c|}
\hline & $\begin{array}{l}\text { All causes } \\
(n=146) \\
N(\%)\end{array}$ & $\begin{array}{c}\text { Biliary atresia } \\
(n=35) \\
N(\%)\end{array}$ & $\begin{array}{l}\text { Other diagnoses } \\
\qquad \begin{array}{c}(\mathrm{n}=111) \\
\mathrm{N}(\%)\end{array}\end{array}$ \\
\hline Jaundice & $146(100)$ & 35 (100) & $111(100)$ \\
\hline Enlarged liver & 139 (95) & $35(100)$ & $104(94)$ \\
\hline Enlarged spleen & $76(52)$ & $18(51)$ & $58(52)$ \\
\hline \multicolumn{4}{|l|}{ Colour of stools } \\
\hline Pigmented & $44(30)$ & $2(6)$ & $42(38)$ \\
\hline Slightly pale & $33(22)$ & $4(11)$ & $29(26)$ \\
\hline Pale & $69(47)$ & $29(83)$ & $40(36)$ \\
\hline
\end{tabular}

Adapted from: Lee WS, et al. Clinical features differentiating biliary atresia from other causes of neonatal cholestasis. Annals Acad Med Singapore 2010; 39: 648-654.

Table 3: Factors contributing to delayed referral in 65 infants with neonatal cholestasis seen at University of Malaya Medical Centre, Kuala Lumpur

\begin{tabular}{lcc}
\hline Factors & $\mathbf{n}$ & $\mathbf{\%}$ \\
\hline Repeated reassurances by primary health care staffs & 17 & 26 \\
Failure of medical services at referring hospital & 7 & 11 \\
No actions on blood investigations & 1 \\
Delayed review of nuclear medicine scan & 1 & 1 \\
Failed percutaneous cholangiogram & 1 & 1 \\
Inconclusive liver biopsy & 2 \\
Liver biopsy results unavailable for review & 5 & 8 \\
Incorrect diagnosis & 8 & 55 \\
Reluctance of parents for referral & 5
\end{tabular}

Adapted from: Lee WS. Pre-admission consultation and late referral in infants with neonatal cholestasis. J Paediatr Child Health 2008; 44: 57-61.

performed before 60 days of age, the percentage of infants with bile flow is between $67 \%$ and $82 \%$ $(15,16)$. This is reduced to $45-62 \%$ if the surgery is performed after 60 days $(15,16)$. However, a delay in the referral of infants with neonatal cholestasis for appropriate investigations and management remains common $(12,17)$.

\section{Reasons for delayed referral and diagnosis}

Failure to realise this overlapping clinical features has often lead to delayed referral, diagnosis and appropriate management (Table 3) (12). In UMMC, the median age of referral for infants with neonatal cholestasis was 59 days (7). Factors contributing to a delay in referral included repeated false reassurance about the benign nature of neonatal cholestasis by medical and para-medical staffs, failure of hospital services, and parental refusal for referral (12).

\section{Liver histology in neonatal cholestasis}

Many biochemical and radiological methods are available to differentiate obstructive from nonobstructive causes of neonatal cholestasis, though none are perfect (11). Histological examination of the biopsy materials obtained from infants with neonatal cholestasis has been found to be highly specific and sensitive in differentiating BA from other non-obstructing causes $(11,18)$. Liver biopsy can 
be performed safely even in the smallest of infants $(11,18)$. Bile ductular proliferation, bile plugging, multinucleated giant cells, focal necrosis of the parenchyma, extramedullary haemopoiesis and inflammatory cell infiltrate in the portal area are all well-recognised histological features of BA (18). Most of these features are more commonly seen in older infants with BA with advanced stages of biliary cirrhosis (19).

However, it should be remembered that the histological features of biliary atresia is dynamic. There remains considerable overlap in the histological features of BA and other non-obstructive causes of neonatal cholestasis (Table 4) (20). Early in life, characteristic features of obstruction may not be obvious (Figures 1 \& 2) (20). The staining of the liver biopsy tissue with a special stain for biliary epithelium helps to make an accurate diagnosis of biliary atresia (Figure 3) (21).

\section{Scoring system in the interpretation of histology in neonatal cholestasis}

Because of the non-specific nature of the histology in cholestatic neonatal liver disease, many authors

Table 4: Histological features of neonatal cholestasis (Brough \& Bernstein, 1969)

Biliary atresia $(n=58)$

Major features

Minor features

Bile ductular proliferation (100\%)

Portal fibrosis $(47 \%)$

Bile plugs in dilated ducts $(40 \%)$

Giant cell transformation (25\%)

Portal and/or lobular inflammatory infiltrate (28\%)

Neonatal hepatitis $(n=29)$

Major features

Hepatocellular damage and hepatitis (100\%)

Minor features

Giant cell transformation (variable)

Bile ductular proliferation (14\%)*

Bile stasis (almost exclusively intracellular and canalicular)

Portal fibrosis - slight

* Bile ductular proliferation was generally mild and was focally or irregularly distributed. In addition, the distortion and irregularity of the proliferating ducts, characteristically seen in biliary atresia, were lacking.

Adapted from: Brough AJ and Bernstein J. Liver biopsy in the diagnosis of infantile obstructive jaundice. Pediatrics 1969; $43: 519-526$.

Table 5: Outcome of 57 children with biliary atresia referred to University Malaya Medical Centre, Kuala Lumpur; 1996 - 2004

\begin{tabular}{lcc}
\hline & $\mathbf{n}$ & \% \\
\hline Alive, no morbidity & 16 & 28 \\
Alive, major morbidity & 5 & 9 \\
Alive, liver transplant & 2 & 4 \\
Died, without surgery & 9 & 16 \\
Died, unsuccessful surgery & 23 & 40 \\
Died, after liver transplant & 2 & 4 \\
\hline Total & 57 & 100 \\
\hline
\end{tabular}

Adapted from: Lee WS, et al. Outcome of biliary atresia in Malaysia. J Paediatr Child Health 2009. 


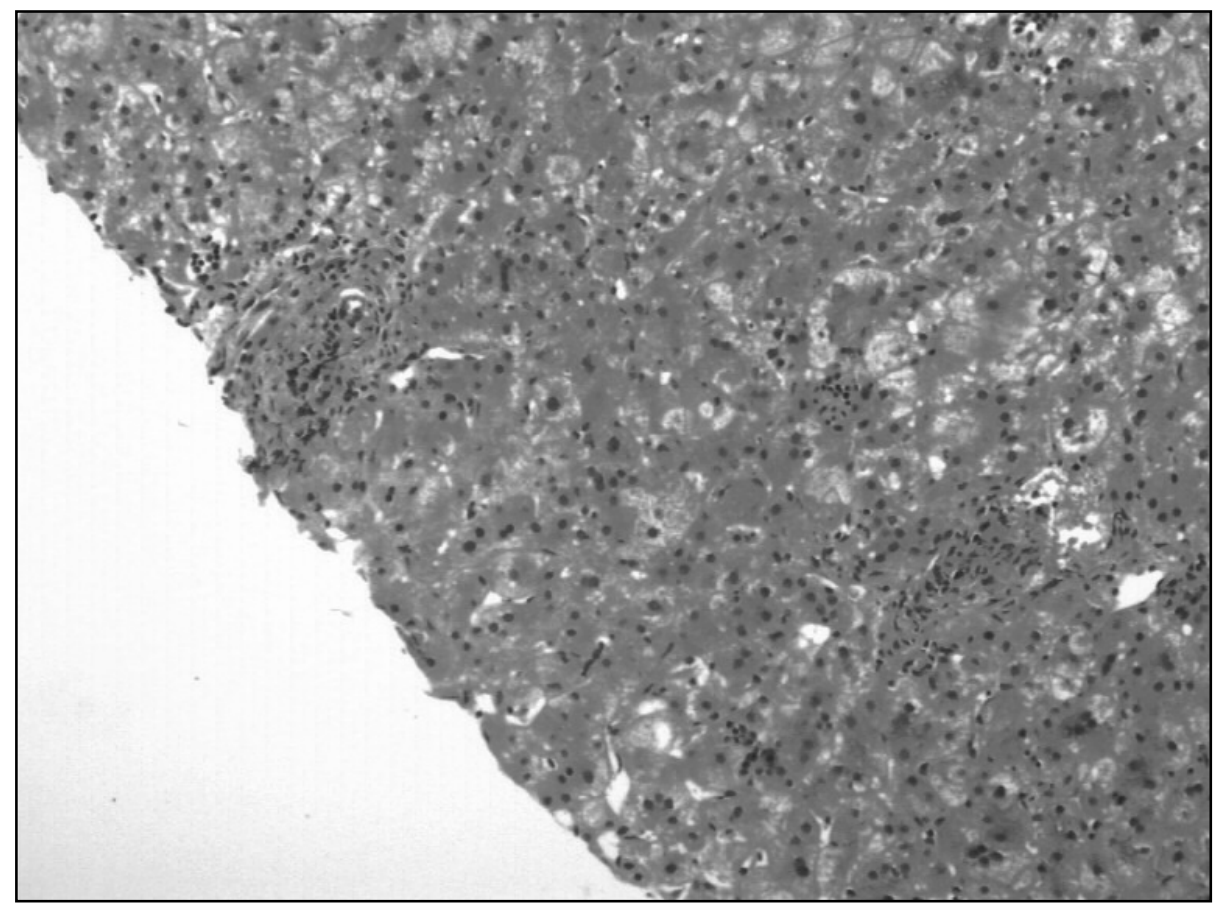

Figure 1: Liver biopsy of a patient with biliary atresia obtained at 34 days of age

A portal tract was shown here with no obvious bile ductular proliferation. There was hepatocytic degeneration and swelling (H\&E, $x$ 200).

Adapted from: Lee WS, et al. Diagnostic usefulness of a 7-feature, 15-point scoring system in the interpretation of liver histology in neonatal cholestasis. World J Gastroenterol 2009.

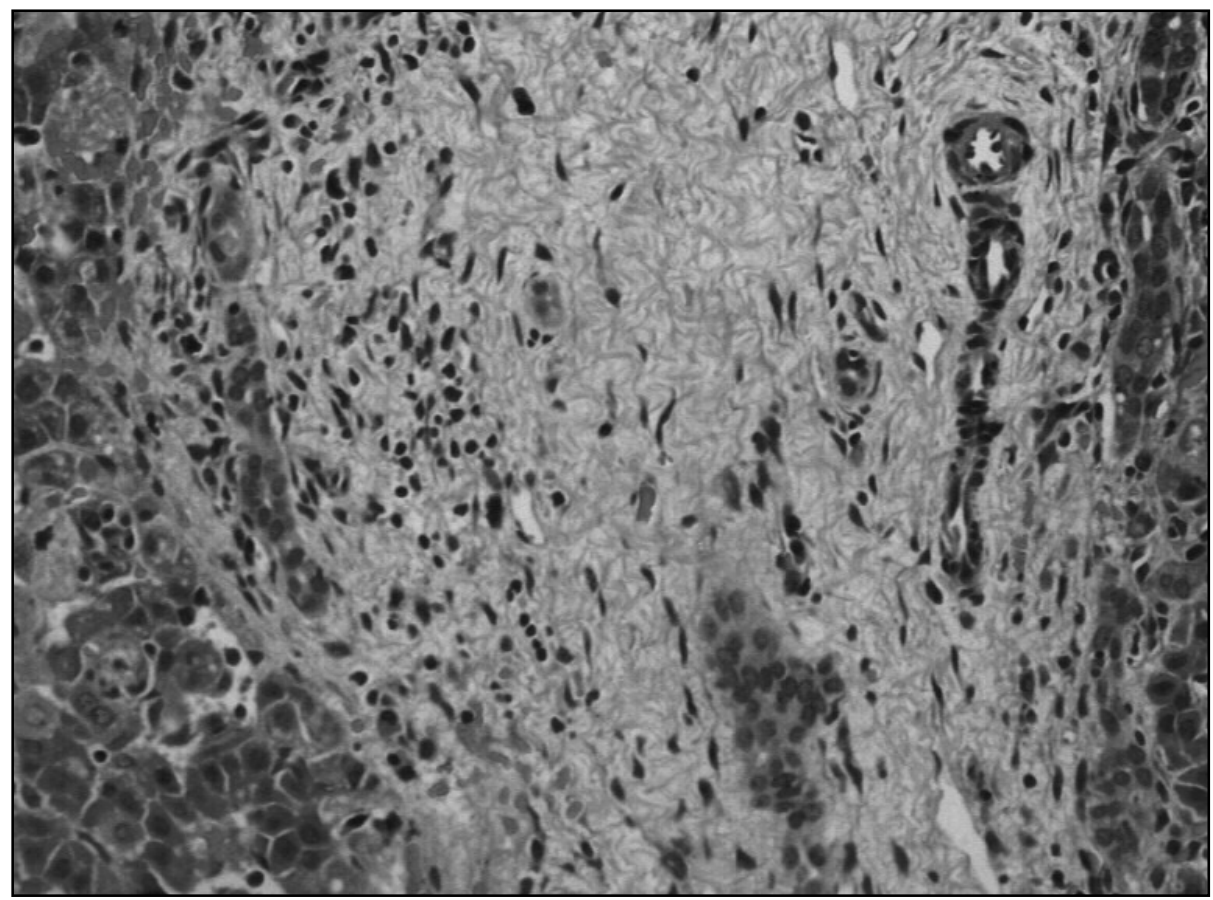

Figure 2: Liver biopsy of the same patient obtained at 45 days of age

A portal tract was shown here with marked bile ductular proliferation, and bile plug in bile ductules, typical of biliary atresia (H\&E, $x$ 200).

Adapted from: Lee WS, et al. Diagnostic usefulness of a 7-feature, 15-point scoring system in the interpretation of liver histology in neonatal cholestasis. World J Gastroenterol 2009. 


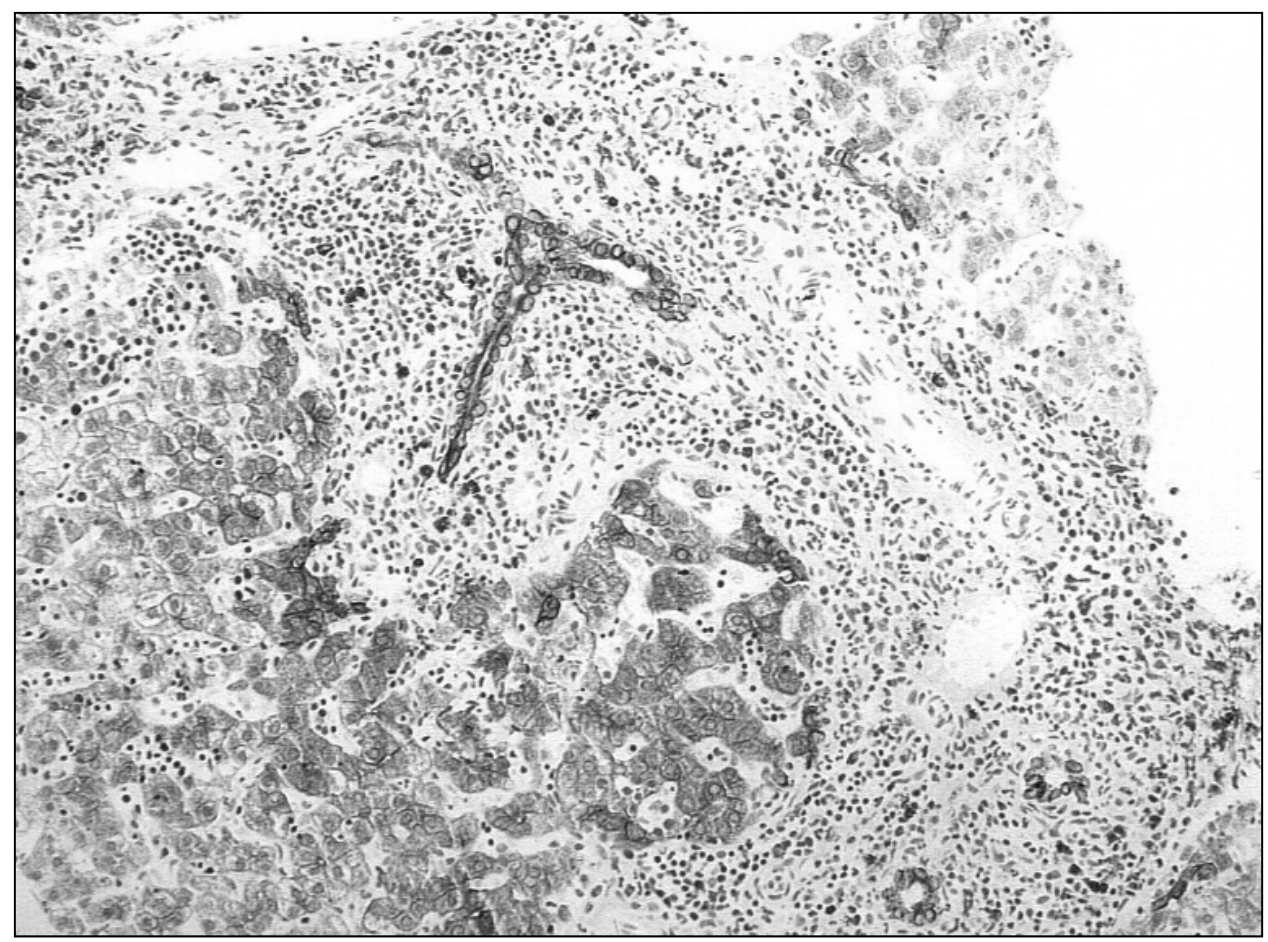

Figure 3: Liver biopsy stained with MnF116 in biliary atresia showing a portal tract with marked bile ductular proliferation

Marked bile ductular proliferation with tortuosity within a portal tract (MnF116, x 200).

Adapted from: Lee WS, et al. Diagnostic usefulness of a 7-feature, 15-point scoring system in the interpretation of liver histology in neonatal cholestasis. World J Gastroenterol 2009.

have attempted to devise various histological scoring systems. The scoring system devised by Zerbini et al suffered from being too complex (22), and has not been adopted widely.

A histology scoring system was devised at the Department of Paediatrics, UMMC, based on 7-feature (portal ductal proliferation, bile plugs in the ductules, porto-portal bridging, lymphocytic infiltration in the portal region, multinucleated hepatocytes, neutrophilic infiltration, hepatocellular swelling), 15-scoring (0-15) scoring system (21). With this system, Lee and Looi reviewed blindly 84 liver biopsy specimens obtained from 78 infants with neonatal cholestasis. A score of 7 was found to have the best overall diagnostic utility to differentiate BA from other intrahepatic cholestasis histologically (sensitivity for BA $88 \%$, specificity $94 \%$ and accuracy $92 \%$ ) (21).

\section{Biliary atresia}

BA is an idiopathic condition characterised by progressive fibrosing obliteration of both intra- and extrahepatic bile ducts (23). It is the most important cause of neonatal cholestasis worldwide, including Malaysia $(10,23)$. It is also the most important indication for childhood liver transplantation the world over (24). The main challenges facing infants and children with BA in Malaysia is late surgery leading to a poor outcome (Table 5) $(10,12)$.

\section{Outcome of biliary atresia in UMMC, Malaysia}

The outcome of infants with BA with unsuccessful surgery is poor (23). Without liver transplantation, the median age of survival was 15 months (23). In those with unsuccessful surgery, liver transplantation is essential to ensure long term survival. In the United Kingdom, where surgery for BA is centralized to three regional centres, the 4-year actuarial survival (with liver transplantation) was $89 \%$, while the 4-year actuarial survival with native liver was $51 \%$ (25). In UMMC, a study involving 57 infants with BA from 1996 to 2005 showed that the 2-year actuarial survival (with liver transplantation) was $40 \%$, while the 2 -year actuarial survival with native liver was 37\% (10). 
Table 6: Outcome of biliary atresia in UMMC (1996-2004) as compared to other reported series in the world.

Centre

\begin{tabular}{lll}
\hline Japan & 60 & 75 \\
Taiwan & 35 & 42 \\
England and Wales & 51 & 89 \\
United States & 56 & 91 \\
France & 40 & 74 \\
Canada & 33 & 85 \\
Switzerland & 37 & 92 \\
Malaysia (UMMC) & 37 & 40 \\
\hline
\end{tabular}

Adapted from: Lee WS, et al. Outcome of biliary atresia in Malaysia. J Paediatr Child Health 2009.

Two factors contributed to the poorer surgical outcome and actuarial survival for BA in UMMC as compared to other more advanced countries in the world. They are a delay in referral for infants with neonatal cholestasis for appropriate diagnosis and surgery for BA, as well as limited availability of liver transplantation in children who have end stage liver failure in Malaysia (10). Nevertheless, the survival rate with native liver in children with $B A$ operated at UMMC is comparable to other countries in the world (Table 6) (10).

\section{Future challenges}

The challenges of neonatal cholestasis and BA in Malaysia are manifold. Firstly, health care providers need to be aware of the potentially serious nature of an infant with prolonged cholestatic jaundice and pale stools. Obstructive causes need to be excluded in the first instance. Secondly, infants suspected of having BA should be managed in a centre with appropriate medical and surgical expertise. Finally, liver transplantation service in Malaysia should be expanded so that more children with end stage liver failure can receive life-saving surgery.

\section{References}

1. Soriano $H$. Normal hepatocyte function and mechanisms of dysfunction. In: Walker WA, Goulet O, Kleinman RE, Sherman PM, Shneider
BL, Sanderson IR (eds), Pediatric Gastrointestinal Disease: Physiology, Diagnosis, Management. Hamilton, Ontario; BC Decker; 2004: 89-97.

2. Ruchelli ED. Developmental anatomy and congenital anomalies of the liver, gallbladder, and extrahepatic biliary tree. In: Russo P, Ruchelli E, Piccoli DA (eds), Pathology of Pediatric Gastrointestinal and Liver Disease. New York; Springer-Verlag; 2004: 191-202.

3. Watkins JB. Neonatal cholestasis: developmental aspects and current concepts. Sem Liver Dis 1993; 13: $276-288$.

4. McLin VA, Balistreri WF. Approach to neonatal cholestasis. In: Walker WA, Goulet O, Kleinman RE, Sherman PM, Shneider BL, Sanderson IR (eds), Pediatric Gastrointestinal Disease: Physiology, Diagnosis, Management. Hamilton, Ontario; BC Decker; 2004: 1079-1093.

5. Balistreri WF. Neonatal cholestasis. J Pediatr 1985; 106: 171-84.

6. Lee WS. Neonatal Cholestasis in Malaysian Infantsa Consultancy Practice Study. Thesis submitted for the Degree of Doctorate in Medicine (M. D.), University of Malaya, 2007.

7. Lee WS, Chai PF. Clinical features differentiating biliary atresia from other causes of neonatal 
cholestasis. Ann Acad Med Singapore 2010; 39: 648654.

8. Miethke AG, Balistreri WF. Approach to neonatal cholestasis. In: Kleinman RE, Goulet O, MieliVergani G, Sanderson IR, Sherman PM, Shneider BL, (eds), Pediatric Gastrointestinal Disease: Physiology, Diagnosis, Management. Hamilton, Ontario; BC Decker; 2008: 789-801.

9. Lee WS, Chai PF, Boey CM, Looi LM. Aetiology and outcome of neonatal cholestasis in Malaysia. Singapore Med J 2010; 51: 434-439.

10. Lee WS, Chai PF, Lim KS, et al. Outcome of biliary atresia in Malaysia-a single centre study. J Paediatr Child Health 2009: 45: 279-285.

11. Lai MW, Chang MH, Hsu SC, et al. Differential diagnosis of extrahepatic biliary atresia from neonatal hepatitis: a prospective study. J Pediatr Gastroenterol Nutri 1994; 18: 121-127.

12. Lee WS. Pre-admission consultation and late referral in infants with neonatal cholestasis. J Paediatr Child Health 2008; 44: 57-61.

13. Bezerra JA, Balistreri WF. Cholestatic syndromes of infancy and childhood. Semin Gastrointest Dis 2001; 37: 47-50.

14. Moyer V, Freese D, Whitington PF, et al. Guideline for the evaluation of cholestatic jaundice in infants: recommendations of the North American Society for Pediatric Gastroenterology, Hepatology and Nutrition. J Pediatr Gastroenterol Nutri 2004; 39: 115-128.

15. Howard ER. Extrahepatic biliary atresia: a review of current management. Br J Surg 1983; 70: 193-197.
16. Ohi R. Biliary atresia: a surgical perspective. Clin Liver Dis 2000; 4: 779-804.

17. Mieli-Vergani G, Howard ER, Portman B, et al. Late referral for biliary atresia-missed opportunities for effective surgery. Lancet 1989; 333: 421-423.

18. Hays DM, Wooley MM, Snyder WH, et al. Diagnosis of biliary atresia: relative accuracy of percutaneous liver biopsy, open liver biopsy and operative cholangiography. J Pediatr 1967; 71: 598-607.

19. Brough AJ, Bernstein J. Liver biopsy in the diagnosis of infantile obstructive jaundice. Pediatrics 1969; 43: 519-526.

20. Craig JM, Landing BH. Form of hepatitis in the neonatal period simulating biliary atresia. AMA Arch Pathol 1952; 54: 321-333.

21. Lee WS, Looi LM. Diagnostic usefulness of a 7-feature, 15-point scoring system in the interpretation of liver histology in neonatal cholestasis. World J Gastroenterol 2009; 15: 53265333.

22. Zerbini MC, Gallucci SD, Maezono R, et al. Liver biopsy in neonatal cholestasis: a review on statistical ground. Mod Pathol 1997; 10: 793-799.

23. Hartley JL, Davenport M, Kelly DA. Biliary atresia. Lancet 2009; 374(9702): 1704-1713.

24. Kamath BM, Olthoff KM. Liver transplantation in children: update 2010. Pediatr Clin North Am 2010; 57: 401-414.

25. Davenport M, De Ville de Goyet J, Stringer MD, et al. Seamless management of biliary atresia in England and Wales (1999-2002). Lancet 2004; 363 (9418): 1354-1357. 